\title{
Indigenous Concept TATTOO in Publicistic Discourse of Modern Multinational English
}

\author{
O. V. Domnich \\ Zaporozhzhya National University, Zaporizhzhya, Ukraine \\ Corresponding author. E-mail: olga-nika02@znu.edu.ua
}

Paper received 21.06.20; Accepted for publication13.07.20.

https://doi.org/10.31174/SEND-Ph2020-234VIII69-02

Abstract. The concept TATTOO belongs to indigenous linguocultural imported concepts and operates in the conceptual sphere of multinational English. The lexical unit "tattoo" is represented by a wide word-formation nest, which includes derivatives, namely nouns, verbs, adjectives, participle I and participle II (formed with the English affixes), which are formed as a result of conversion and affixation.

Keywords: concept TATTOO, lexical unit "tattoo", indigenous concept, publicistic discourse.

\author{
Traditional tattooing established \\ a great importance in the culture, \\ as it signifies ranking, honor, rituals, \\ protection, and other significance \\ related to the community. \\ J.V. Santander
}

Introduction. The issues related to the representation of corporal codes in various linguocultures (American, Russian, Chinese, Japanese, Polynesian, etc.) are of topical interest and are the object of scientific research of a number of modern linguists (A.D. Borokhov (2018), E.S. Vorobyeva (2016, 2018), L.A. Melnikova (2015, 2018), O.A. Ovsyannikova (2017), I.E. Okholina (2017), J.A. Follet (2009), C. Nyssen (2017), M. Patterson (2018), J. Camacho and W. Brown (2018), and others.

In the works of contemporary scientists, topical issues and various aspects of the study of different types of "body painting" are touched upon in the etymological aspect $[12$; 21], sociocultural [7; 9; 23], culturological [18], linguistic $[10 ; 11]$, historical $[14 ; 18]$, gender $[2 ; 7]$, sociological $[3$ $7 ; 8 ; 13 ; 14 ; 20]$, psychological $[1 ; 3 ; 8 ; 13 ; 14 ; 20]$, medical [1], in the aspect of criminology [15; 19], and the studies concerning the specifics of the functioning of tattoos in modern society are conducted as well [1-3; 7-11; $13-20 ; 23]$. Thus, research in the field of "body art" is undertaken quite widely, the most studied aspects are sociological, psychological and historical, while the linguistic aspect is investigated insufficiently, and this fact determines the relevance of this work, and requires scientific investigation in the context of reconstructing of the concept TATTOO as well.

The aim of the article is to identify the features of the processes and results of borrowing of indigenous linguocultural concepts, using the concept TATTOO in the publicistic discourse of modern multinational English as an example. Achieving this purpose involves accomplishing the following tasks: to create a corpus of indigenous borrowed concepts relevant to the modern polynational English language in various linguoareals (North American, Australian-New Zealand, Asian and African); to form a conceptual matrix of indigenous concepts and identify the main domains in it; to reconstruct the indigenous concept TATTOO in the publicistic discourse.

Methods and material. The source base of the study is formed by 1) printed and electronic newspaper and magazine publicism (publicistic texts on socio-political issues), dating 2014-2020 and represented by 506 items (of eight national and regional varieties of modern multinational English), the total amount is 17321 pages, and (2) public speeches of famous politicians (transcripts of these speeches and performances), dating 2014-2020 and represented by 400 items, the total amount is 2314 pages; 3 ) lexicographical editions of eight national-territorial and regional variants of modern polynational English (general explanatory dictionaries of national-territorial and regional variants of polynational English and special dictionaries of indigenous vocabulary in English, as well as glossaries).

The methods of the work are determined by the characteristics of the subject and material of the study and by the integrated approach to its consideration. In the process of writing the paper, the following methods were applied: sociolinguistic method, descriptive method, methods of cognitive linguistics, etymological analysis, cultural linguistic analysis, component analysis, derivational analysis, the method of dictionary definition analysis, elements of comparative analysis, quantitative calculations.

Results and discussion. Linguocultural concepts, verbalized in indigenous lexical units, function in the minds of representatives of modern national and cultural communities in socio-political discourse and define the space of indigenous ethnic groups in such domains as PEOPLE, NATURE and CULTURE which are bound and correlated [3, c. 22]. The conceptual worldview of the English-speaking ethnic groups is formed by universal English concepts and unique (endemic) indigenous concepts. The concept TATTOO belongs to indigenous linguocultural imported concepts and operates in the conceptual sphere of multinational English.

\begin{tabular}{|c|c|}
\hline $\begin{array}{c}\text { CONCEPTUAL MATRIX } \\
\text { (according to S.A. Zhabotinskaya } \\
(2008,2009))\end{array}$ & $\begin{array}{c}\text { the world /space of indige- } \\
\text { nous ethnic groups }\end{array}$ \\
\hline DOMAIN & culture \\
\hline PARCEL & spiritual culture \\
\hline CONCEPT & $\begin{array}{c}\text { religion, mythology and tra- } \\
\text { ditions }\end{array}$ \\
\hline $\begin{array}{c}\text { LEXEME } \\
\text { thattoo }\end{array}$ \\
\hline
\end{tabular}

Table 1. The conceptual matrix of indigenous linguocultural concepts in the conceptual sphere of multinational English

When forming the conceptual matrix of indigenous linguocultural concepts in the conceptual sphere of multinational English (Table 1.), it should be noted that the conceptual matrix "world / space of indigenous ethnic 
groups" is represented by the domain "culture", which is revealed through the parcel "spiritual culture" and is represented by the concept "religion, mythology and traditions", which includes subconcept "tattoo" and is verbalized through the lexical unit "tattoo".

Having analyzed the publicistic discourse of multinational English language, we find that this concept, verbalized by the lexical unit "tattoo", operates in eight nationalterritorial and regional varieties of the multinational English language: American English, Canadian English, Australian English, New Zealand English, South African English, Kenyan English, Indian English, Singapore English. The English-language notion of the lexical unit "tattoo" is best defined in the explanatory dictionary "Online Dictionary by Merriam-Webster" and means the following: tattoo "1. a mark, figure, design, or word intentionally fixed or placed on the skin. 1a one that is indelible and created by insertion of pigment under the skin. $1 \mathrm{~b}$ one that is temporarily applied to the skin, resembles a permanent tattoo, and usually lasts for a few days to several weeks. 1c one that is composed of scar tissue intentionally created by cutting, abrading, or burning the skin. 2. the act of tattooing: the fact of being tattooed" [22].

Quantitative analysis of the lexical unit "tattoo" in the publicistic discourse proves that the highest frequency of it is observed in the North American linguoareal - 46.9\%, ((AmE) «The girl al-legedly received a message from him in July in which he performed a sex act and authorities said they identified him by his tattoos» [33, c. 3]), and the lowest frequency - in the Asian linguoareal - 4.6\% ((SgE) «The three-day Tattoo Malaysia Expo, which started on Friday, drew participants from 35 countries» [31, c. 7]). In the Australian-New Zealand linguoareal there are $28.8 \%$ ((NZE) «Breakfast's Jenny-May Clarkson shows off 'magic' wedding ring tattoo» [22)), and in the African linguoareal - $19.7 \%$ ((KeE) «For some people this might have meant getting a tattoo of their lover's name, image or initials» $[24$, c. 6]).

On the basis of the analysis of the frequency of the lexical unit "tattoo" in eight national-territorial and regional varieties of multinational English (Diagram 1.), we conclude that the highest rate is represented in the North American linguoareal $(46.9 \%)$, as the culture of tattooing has been topical and quite relevant in that area for a long time (since the end of the XIX - beginning of the XX century). This fact is reflected in the institutional discourse (namely, its publicistic type) by the presence of high frequency. The culture of tattoo is greatly common in the USA [13]; the authors conclude that tattooed persons (especially females) are rated as stronger and more independent than non-tattooed ones [13]. A few words of comment are obviously necessary here as an extralinguistic comment. One of the founders of the promotion of tattoo as a culture in North America is Martin Hildebrandt, who started off with tattooing signs of military service and military affiliation (regimental symbols and commemorative signs of a military campaign) to bodies of soldiers for their identification during the Civil War in the USA in the middle of the XIXth century (1861-1865). To be more precise, in the 1860s, this German immigrant continued his tradition of tattooing, launched his own tattoo studio and developed a reputation of a fairly popular tattoo artist in North America [4].

In the middle of the XXth century, a powerful impetus was provided for the development of a current tattoo culture as an art, creativity and self-expression, correspondently. It must be admitted that the reason is that the development of a subcultural movement in the USA and the formation of subgroups representing this movement (hippies, bikers, feminists, etc.). Thus, the tattoo becomes part of the subculture, namely, a rather important and distinctive part of it. The second half of the last century was marked by the evolution and extension of a tattoo culture. To put the same thing in another form, "Preceding the Tattoo Renaissance of the 70s and 80s, the political and social climate of activism throughout the west facilitated the birth of a new, unabashed client base for tattoos. The skins of counter-culture groups like the black resistance, gay liberationists, and women's rights advocates were adorned with tattoos embodying their identities of dissent. It is this steadfast spirit of rebelliousness - a vocal discontent with the status quo - that courses through the veins, and ink, of Indomito [tattoo]" [17]. Another extremely important form of a tattoo culture is that famous personalities (Guns N 'Roses, Black Sabbath and others) got a tattoo done, and also a significant number of American celebrities have "body painting" and "set the tone" in the contemporary society, which was instantly picked up and embodied by the young generation of this linguocultural community. The contemporary scientist characterizes tattoo in the modern society in such a way: "Like a snapshot, the tattoo is a dialectic record of the mother-father relationship, of desires for closeness and distance, commonality and difference, identification and individuation" [20].

The important point is that a tattoo culture in this linguoareal was transformed from a subculture (representatives of various subcultures) into mass culture (representatives of the North American ethnic groups). It is worth pointing out that the popularity of tattoos among young generation in the North American linguoareal grew into a large-scale involvement in the 70s of the XXth century. Over time, a tattoo culture and one of its kinds - a "body art" covers increasingly the larger areas of the globe. During this time, a great interest in the human body as an alive artistic material arose. In such a way, a "body art", as a kind of an art, came into existence. The evolution of various tattoo styles (ethnic style, old school style, new school style, etc.) has developed since that time. Since the beginning of the XXIst century, the tattoo movement has transformed into a huge industry with a significant number of trends, styles, schools of famous artists and their representatives $[5]$.

As the general data point, the lowest frequency of the lexical unit "tattoo" is observed in Asian linguoareal (e.g., $1.8 \%$ - in $\mathrm{SgE}$ ). This rather small amount indicates, as we assume, that in Asian countries local traditions and cultures are strong enough, and Western "fashion trends" and imported concepts (the term of V.I. Karasik) fail to take root in the conceptual sphere of English in Asian linguoareal.

Partial analysis of the lexical unit "tattoo" in the publicistic discourse proves that out of the total number of ways to verbalize it, the concept TATTOO is verbalized using the most frequent lexical units and the direct nominee is expressed by a noun $-82.6 \%$ ( (AuE) «As the interview unfolds, I can see that Bateman's arms are riddled with tiny white scars, partially hidden by tattoos [32, c. 11]). Verbal and adjective forms are presented in equal amounts $-8.7 \%$ 
each, respectively, ((AuE) «He is large, beefy, and tattooed》 [27, c. 7]; (AmE) «A fictionalized account of the true story of Lale Sokolov, an Auschwitz inmate forced to tattoo numbers on fellow prisoners $(F)(P)$ Harper» $[34, \mathrm{c}$. 2]).

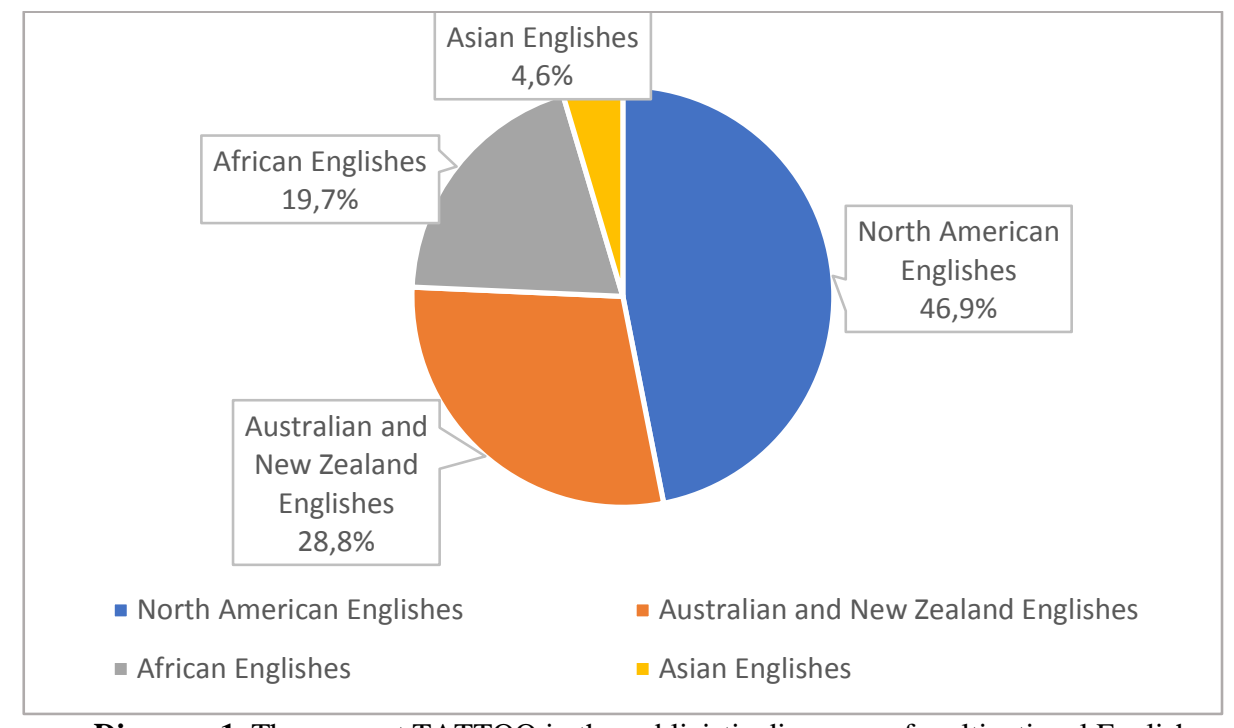

Diagram 1. The concept TATTOO in the publicistic discourse of multinational English

The direct nominee of the concept TATTOO is expressed by a noun, this is due to the borrowing of nomens that represent the realities of indigenous ethnic groups, namely, concepts from the sphere of nature and culture of indigenous linguocultural communities. Verbal and adjective forms are represented in insignificant quantities, as they are lexical units verbalizing foreign cultures concepts that are borrowed rarely.

The derivational analysis of the lexical unit "tattoo" in the publicistic discourse proves that derivatives are formed in two ways: conversion $-14.4 \%$ ((AmE) «Before that meet, Christon tattooed wings on the outer parts of his lower legs» [33, c. 3]) and affixation, namely, suffixation $-85.6 \%$ ((CaE) «In 2012, about halfway through the Jets' first season back in Winnipeg, McReynolds had his left shoulder tattooed with the Thrashers' logo» [30, c. 6]). The most productive affix of the English language is "-ed", which forms $64.2 \%$ of derivatives; as a result of affixation, an adjective form is $21.4 \%$ ((AmE) «A screen showed $a$ photo of the tattooed hand of defendant Aaron Hernandez (lower left) in court Wednesday» [26, c. 3]) and Past Participle $-42.8 \%,((\mathrm{CaE})$ «I am a 72 -year-old Canadian, who is fortunate enough to have been to every province and territory, of Canada and have lived in most of them. Hell, I even have the maple leaf tattooed on my chest» [29, c. 16]). We also point out the participation of the agentive suffix ". ist", $21.4 \%$ of derivative lexical units are formed with the help of it ((AuE) «Our monthly skin tattooists specializes in eyelineleyebrow/plasma therapy areola/tattoos Ask about our 1/2 price loyalty club scheme membership special» [28, c. 11]).

The derivational analysis showed that most derivatives $(85.6 \%)$ are formed by the method of suffixation using such suffixes as "-ed" and "-ist". And the smallest number of derivatives - by the method of conversion (14.4\%).
Among derivatives, the verbal form dominates $-42.8 \%$, the adjective form and nouns are $21.4 \%$ each, respectively.

Conclusions and perspectives. Summing up the results of our research we would like to note the concept TATTOO is linguocultural, specialized (namely, sociocultural), customary, specific, individual and group (namely, microgroup), and narrowly focused and highly specific as it can be verified in the typology of this concept [16]. We suppose that, probably, the culture of tattooing is more developed in the cold and cool linguo-regions of functioning of multinational English (North American and AustralianNew Zealand) than in warm and hot linguo-regions (Asian and African), since in the latter (namely, in Asian linguoareal), the lexical unit "tattoo" is presented in a single amount (e.g., in Singapore English), and in the African linguoareal there is a small amount of patterns of indigenous borrowed lexical unit.

There is a reason to suppose that the importance of evolution of a tattoo culture is also evidenced by the fact that a number of magazines devoted to this topic are published in North America, mass media, educational institutions and scientific institutes are engaged in the scientific side and popularize issues related exclusively to a current tattoo culture and a "body art". The concept TATTOO is represented in the conceptual sphere of modern multinational English not only as a concept, but also as an established lingual and cultural phenomenon, functioning in its national-territorial and regional varieties, and expressing values that are significant for a modern English-speaking society.

The prospects for the further research are to reconstruct the concepts functioning in the conceptual sphere of a multivariate system of English, as well as to investigate the conceptual and lingual specifics of the indigenous component based on the analysis of the institutional discourse of modern multinational English.

\section{REFERENCES}

1. Borokhov A.D. Tattoos Multiaxial classification for an Integral of assessment psychopathology // Medical psychology in Russia, 2018. Vol. 10. №1 (48). P. 1-20. DOI: 1024411/22198245-2018-11100

2. Brockhaus and Efron Encyclopedic Dictionary: Volume XXXIIA (64). Thai - Termites. St. Petersburg: "Publishing", Brockhaus-Efron, 1901 (1995).

3. Domnich O.V. Critical analysis in the study of socio-political 
discourse of modern multinational English // Odessa Linguistic Bulletin, 2019. Vol. 14. P. 13-26. DOI 10.32837/olj.v0i14.807

4. Melnikov I.V. Evolution of a pectoral drawing. St. Petersburg: LitRes, 2012a

5. Melnikov I.V. Tattoo skills from Russia to Oceania. St. Petersburg: LitRes, 2012b.

6. Melnikova L.A. Tattoo as a form of representation of sociocultural codes of visibility. Abstract... cand. of culturology. Komsomolsk-on-Amur, 2015. $22 \mathrm{p}$.

7. Melnikova L.A. The visual representation of the bodily codes of the Russian and Chinese youth // Territory of New Opportunities. Herald of VSUES, 2018. №1. P. 146-155. DOI: dx.doi.org/10/24866/VVSU/2073-3984/2018-1/146-155

8. Okholina I.E. TATTOO as the component of the key concept "ART" in the modern American linguistic culture // Bulletin of TSPU, 2017. №3 (180). P. 18-23. DOI: 10.23951/1609624X-2017-3-18-23

9. Ovsyannikova O.A. Tattoo through the prism of semiotics // Tambov University Bulletin. Social Sciences, 2017a. Vol. 3. \# 2 (10). P. 82-85. DOI: 10.23951/1609-624X-2017-3-18-23

10. Ovsyannikova O.A. The tattoo is a sociocultural phenomenon // Science. Society. State, 2017b. Vol. 5. №1 (17). URL: http://esj.pnzgu.ru

11. Vorobiyova E.S. The development of motivation to tattooing as a mechanism of identity constructing // Sociological sciences, 2016. №6. P. 41-47.

12. Vorobiyova E.S. What the tattooed body tells: the gender aspect in the experience of visual sociology // Inter, 2018. №16. P. 70-80. DOI: 10.19181/inter.2018.16.6

13. Broussard K. A., Harton H.C. Tattoo or taboo? Tattoo stigma and negative attitudes toward tattooed individuals // The Journal of Social Psychology, 2018. №158 (5). P. 521-540. DOI: 10.1080/00224545.2017.1373622

14. Buss L., Hodges K. Marked: Tattoo as an Expression of Psyche // Psychological Perspectives, 2017. №60 (1). P. 4-38. DOI: $10.1080 / 00332925.2017 .1282251$

15. Camacho J., Brown W. The evolution of the tattoo in defiance of the immutable definition of deviance: current perceptions by law enforcement of tattooed arrestees // Deviant Behavior, 2018. №39 (8). P. $\quad$ 1023-1041. DOI: 10.1080/01639625.2017.1395669

16. Domnich O.V. The specificity and typology of concept TATTOO in publicistic discourse. 2020. - in print.

17. Graves H. Forever More: The New Tattoo. Berlin: Gestalten Verlag, 2017.

18. Follet J.A. The consumption of tattoos and tattooing: the body as permanent text. $2009 . \quad$ URL: http://citeseerx.ist.psu.edu/viewdoc/download? DOI $=10.1 .1 .819 .4784 \&$ rep

19. Jacques S. What Criminals' Tattoos Symbolize: Drawing on Darwin, Durkheim, and Lombroso // Deviant Behavior, 2017. №38 (11). P. $1303-1317$. 10.1080/01639625.2016.1197606

20. Karacaoglan U. Tattoo and taboo: On the meaning of tattoos in the analytic process // The International Journal of Psychoanalysis, 2012. №93 (1). P. 5-28. DOI: 10.1111/j.17458315.2011.00497.x

21 Nyssen C. Language of Tatau, Ta Tatau, Tattoo. 10 June 2017. URL: http://www.buzzworthytattoo.com/language-of-tatauta-tatau-tattoo/

22. Online Dictionary by Merriam-Webster. URL: merriam-webster.com

23. Patterson M. Tattoo: marketplace icon // Consumption Markets \& Culture, 2018. №21 (6). P. 582-589. DOI: 10.1080/10253866.2017.1334280

24. People Daily. February 21st, 2020.

25. Taranaki Daily News. February 3, 2020. URL: www.stuff.co.nz

26. The Boston Globe. Thursday, March 16, 2017.

27. The Herald. Saturday, January 5, 2019.

28. The Herald. Saturday, August 3, 2019.

29. The Globe and Mail. Wednesday, October 9, 2019.

30. The Globe and Mail. Wednesday, October 16, 2019.

31. The New Paper. Thursday, December 03, 2019.

32. The Perth Voice. Saturday February 22, 2020.

33. USA Today. Monday, October 21, 2019.

34. USA Today. Thursday, September 19, 2019. 